\title{
UNA PROPUESTA TEXTUAL EN LA ERA DE LAS TECNOLOGÍAS DE LA INFORMACIÓN Y LA COMUNICACIÓN ${ }^{1}$
}

\author{
Ángel David Fernández Miravete \\ Universidad de Murcia \\ angeldavid.fernandez@um.es
}

\begin{abstract}
Resumen
En este trabajo reflexionamos sobre una nueva perspectiva de estudio del proceso de comunicación en unas situaciones concretas propiciadas por la sociedad de la información en la que vivimos. Para ello, es preciso superar la aproximación exclusivamente lingüística a la relación existente entre la comunicación y el lenguaje, y ensayar modelos comunicativos más complejos y adecuados para intentar, de este modo, responder a las manifestaciones comunicativas en las que los signos y unidades lingüísticas se combinan con otros signos y unidades de naturaleza no lingüística: hipertextual, audiovisual, electro-informática o virtual. Es a estas nuevas unidades a las que hemos denominado supertextos, cuya relevancia encuentra su lugar en un acto comunicativo condicionado por las nuevas técnicas multimediales de comunicación.

PALABRAS CLAVE: comunicación, multimedia, era de la información, lingüística compleja, supertexto.
\end{abstract}

\begin{abstract}
In this paper we consider a new perspective on the communication process in specific situations of the information society in which we live. To achieve this goal, it is necessary to go beyond a merely linguistic approach to the relationship between communication and language, and more complex communication models are put forward. These are adapted to communicative models in which the signs and language units are combined with other symbols and units of a non-linguistic nature: hypertextual, visual, electro-computing or virtual. These new units are called supertexts, and their importance is analyzed in a communicative act, conditioned by new multimedia communication techniques.
\end{abstract}

KEY WORDS: communication, multimedia, Information Age, complex linguistic, supertext.

\section{Introducción al concepto de supertexto}

La realidad comunicativa actual está dominada por un tipo de producciones textuales, denominadas mediáticas, que implican la necesidad de investi-

1 Este artículo es una revisión ampliada y mejorada de la ponencia pronunciada con el título "Supertexto: un ejemplo de estudio interdisciplinar" en el XXIX Curso de Lingüística Textual, que se celebró en la Universidad de Murcia entre los días 6 y 16 de marzo de 2006. 
gar una explicación que complete la específicamente lingüística con otras aportaciones provenientes de otras ramas del saber que afrontan la comunicación actual y sus lenguajes desde supuestos, modelos y métodos más adecuados a una nueva realidad comunicativa cuyo soporte multimedial condiciona el mensaje lingüístico. Se trata de una nueva perspectiva interdisciplinar que dé respuesta a los nuevos productos comunicativos que empiezan a denominarse textos multimedia o, en expresión de Castells, supertextos.

Es en La era de la información donde Manuel Castells (1997) expone su idea de una sociedad de red en expansión que adquiere dimensiones planetarias. Castells, en su tratamiento sobre la sociedad de red, usa la expresión de supertexto para referirse a los productos simbólicos híbridos que son creados a través de la reflexiva de varias "realidades" al ir «mezclando en el mismo discurso [...] mensajes emitidos desde diferentes niveles de existencia» (1996: 373). Castells nos dice que los supertextos son producidos industrialmente y de manera rutinaria al introducir diferentes narrativas en producciones mediáticas ${ }^{2}$.

Este concepto introducido por Castells resulta interesante al remitir explícitamente a la producción de un texto en cuya construcción intervienen soportes multimediales propios de las nuevas tecnologías de la información y la comunicación y cuyo producto final es el resultado de la intersección de varias narrativas de naturaleza lingüística y no lingüística. Aún más interesante resulta este término en su significación implícita -frente a otros como el de texto multimedia- pues el prefijo super-implícitamente hace referencia a una unidad de comunicación que está por encima de lo exclusivamente textual (lingüístico) pero que no es separable de éste, ni siquiera complementario, sino que lo incluye y necesita para la compresión y eficacia del acto comunicativo en el que se da. Es esta segunda acepción la que más nos interesa, y es por ello que se va a tomar aquí el concepto de supertexto para referirnos a textos que integren todas las características textuales que estudia la Lingüística del Texto $^{3}$, más las propias del nuevo proceso comunicativo: mediáticas, electrónicas y virtuales. Con esto se quiere demostrar cómo el texto producido no sólo se ve condicionado por la producción mediática en el que tiene lugar, sino que también lo está el mismo acto comunicativo. Por

2 Castells utiliza un ejemplo de la televisión comercial norteamericana para demostrar cómo los supertextos son producidos industrialmente al introducir fragmentos culturales y narrativas diferentes en las actuales producciones mediáticas. El ejemplo que utiliza lo extrae del famoso episodio de Murphy Brown. Para saber más véase (Castells 1996: 373 y ss.).

3 Los índices textuales que manejamos son básicamente los recogidos por Beaugrande y Dressler (1972). 
tanto, nos referimos con el término de supertexto a una unidad comunicativa multilingüística, objeto de estudio dentro de una Lingüística comunicativa y nueva Teoría de la comunicación.

Esta nueva perspectiva nace como consecuencia de la necesidad de considerar los nuevos hechos comunicativos que se están dando en nuestra sociedad y que están en continuo desarrollo. Se observa, por el contrario, que los actuales paradigmas se muestran insuficientes ante estos nuevos productos comunicativos; por consiguiente, el nuevo modelo explicativo ha de surgir obligatoriamente desde un estudio transversal y marcadamente interdisciplinar.

Desde que Aristóteles definiera al hombre como zoon logon echon ( $\zeta o 0 v$ $\lambda$ oyov $\varepsilon \xi o v)$ hace más de dos mil años, la reflexión sobre la capacidad de comunicarse mediante la palabra, a la que se añaden las nuevas formas de relacionarse con el mundo, ha llevado a considerar los elementos no estrictamente lingüísticos para intentar aprehender y explicar el hecho comunicativo. Un nuevo enfoque comunicativo, de estrecha colaboración interdisciplinar, que se ha convertido en prioridad para cualquier campo científico.

Esta necesidad de dar respuesta a estos nuevos hechos comunicativos enlaza con lo que Bastardas Boada (1999:17) llama lingüistica compleja:

Una de las consecuencias más felices de incorporar la perspectiva de la complejidad a los fenómenos lingüísticos es terminar con las discusiones acerca del locus de la lengua. Para Saussure era fundamentalmente social, para Chomsky básicamente mental. Para nosotros hoy puede ser social $y$ mental a la vez, sin ver contradicción sino integración y emergencia, dado que, como ya se ha señalado, en los fenómenos sociomentales los objetos pueden no estar en un solo lugar ni pertenecer necesariamente a un solo orden de cosas. Creo que deberíamos concebir la lengua o el fenómeno lingüistico también, pues, como un complejo, y no como un objeto.

La lengua se convierte de esta manera en noosfera, psicosfera y sociosfera en concordancia con su concepción de la naturaleza humana multidimensional y el pensamiento complejo ${ }^{4}$ (Edgar Morin, 1991:121 y ss.).

Los actos comunicativos son, pues, fenómenos complejos que deben explicarse teniendo en cuenta todos los elementos que intervienen en los mismos. Bastardas Boada (1999) reconoce que la nueva y compleja realidad comunicativa exige definir un nuevo paradigma unificador para la lingüística general y las ciencias de la comunicación del siglo XXI.

Los actuales estudios en Teoría de la comunicación se centran en las nuevas relaciones que se establecen entre los elementos clásicos que intervienen

$4 \quad$ Para saber más sobre Edgar Morín y su concepción del pensamiento complejo véase Morin (1992, 1999). 
en el proceso comunicativo pero donde la noción de hipermedia se convierte en fundamental. Se asiste, por un lado, a la elaboración -o reelaboración- de modelos que superan los tradicionales, y por otro lado, se atiende a redefiniciones de algunos de los supuestos clásicos. El resultado es un panorama realmente rico -y complejo- en la investigación lingüística y, por consiguiente, la ausencia de un paradigma al respecto único y globalizador.

Es dentro de este complejo panorama actual cuando se hace necesaria la aportación de nuevos ensayos que traten de arrojar estrategias para abordar el tratamiento de nuevos textos (supertextos) cuyas características definitorias se ven condicionadas y transformadas por las nuevas tecnologías.

En el siguiente epígrafe se expondrán las características constitutivas de texto establecidas por la lingüística textual para, a continuación, establecer las condiciones de producción de estas unidades comunicativas dentro de esta nueva sociedad multimedia. De este modo, se pretende mostrar cómo las unidades comunicativas resultantes son un híbrido entre lo específicamente lingüístico y lo multimedial. Finalmente se hace un análisis más exhaustivo de lo que aquí denominamos supertexto y de cómo el medio afecta no sólo al texto como unidad de comunicación sino a todo el proceso comunicativo en el que se produce.

\section{El enfoque textual de la comunicación}

La Lingüística ha tenido un desarrollo vertiginoso en el siglo XX, más aún si se piensa que los primeros estudios de lingüística estructural todavía no tienen un siglo de existencia. Sin embargo, se puede comprobar cómo ya ha alcanzado un profundo grado de sistematización y ocupa hoy un lugar pionero y modular en buena parte de las ciencias.

Una de las tendencias más importantes que siguió la lingüística el pasado siglo fue la que ha dado en llamarse genéricamente como una lingüistica de la comunicación. Esta corriente de la lingüística no pondrá su punto de mira en el sistema lingüístico en sí, sino en las situaciones de comunicación como creadoras de sentido y en la presencia de un enunciador responsable de los enunciados intencionales por un lado, y un enunciatario que realiza todas las inferencias necesarias para descifrar y comprender el acto comunicativo por otro. Se trataría de una Lingüística del habla o de la enunciación ${ }^{5}$ que integra en su campo de estudio también elementos no estrictamente gramaticales.

A mediados del siglo XX el estudio del discurso se consagra como disciplina teórica. Los trabajos se inician con las Gramáticas de los textos para centrarse en la década de los sesenta y setenta en dos disciplinas: Lingüística del Texto

$5 \quad$ Véase Benveniste (1974a), (1974b). 
y Análisis del Discurso, disciplinas que estudian cuál es la estructura, funcionamiento y procedimientos de textualidad ${ }^{6}$, y cómo intervienen las condiciones de producción y recepción en la elaboración, recepción e interpretación del texto.

Si bien en la década de los setenta se aplicaba habitualmente la noción de discurso para la comunicación oral y texto para la escrita, en la actualidad, sin embargo, ambos términos se utilizan indistintamente para oral y escrito ${ }^{7}$.

Las diferentes teorías sobre el análisis del discurso ofrecen enfoques muy variados sobre el estatuto de la actividad lingüística, ya sea centrándose en el carácter intersubjetivo (la Lingüística enunciativa), la intencionalidad del sentido (Pragmática), o la interacción (enfoques filosófico, sociológico y lingüístico). Más allá de divergencias metodológicas y funcionales, estos estudios coinciden en la interrelación de cuatro parámetros: universo referencial, los participantes en el acto comunicativo, la interacción social y el contexto.

La Lingüística del Texto, que se desarrolla a partir de la década de los setenta, surge para ampliar y modificar las Gramáticas del texto; se aleja de los formalismos reducidos de carácter sintáctico y postula que el texto no es la suma de oraciones sino que es una unidad lingüística global resultado de una práctica discursiva. Los especialistas en Lingüística del texto introducen tempranamente las nociones de contexto y uso. Casi todos los especialistas coinciden en destacar dos grandes ejes de reflexión: el lingüístico y el sociodiscursivo.

Los principios teóricos y metodológicos compartidos por la mayoría de ellos son:

1. el texto es el resultado de una competencia lingüística y comunicativa;

2. dada la diversidad de textos y discursos, una metodología textual debe plantearse el problema de las tipologías textuales en las que se reflejen las característica formales y funcionales de los textos; y

3. una ciencia del texto tiene que explicar cuáles son los procedimientos de planificación y estructura textuales y qué repercusiones tienen en la interacción comunicativa.

Se considera a N. Enkvist ${ }^{8}$ como el fundador de la teoría textual nórdica que defiende que el texto es un objeto lingüístico que se crea en interacción

6 Los funcionamientos, procedimientos e índices textuales permiten diferenciar básicamente a un texto de un no-texto en función del cumplimiento (en diverso grado) de unas reglas o normas textuales.

7 En esta línea, para la noción de supertexto que aquí se presenta tampoco será relevante la separación de rasgos de oralidad y escritura cuyas diferencias vendrán dadas por la actualización en diferente grado de formalidad / informalidad en el manejo de la lengua. 8 Dada la pluralidad de teorías, se presentan, únicamente, tres modelos de reconocido prestigio: La lingüística textual nórdica; el modelo procedimental de R-A. de Beaugrande y W.U Dressler y la semántica interpretativa de F. Rastier. 
social, ya que la lengua es parte integrante de la vida humana y no puede ser considerado como un modelo abstracto. Defiende un modelo procedural (1991) o procesualista de carácter interaccional con el que da respuesta al cómo y porqué de la selección textual.

Por su parte, Beaugrande y Dressler, en su manual ya clásico de Introducción a la lingüística del texto defienden que lo que da identidad al texto no es la gramaticalidad sino la textualidad; ofrecen un modelo interdisciplinario en el que el texto es «un acontecimiento comunicativo que cumple siete normas de textualidad interrelacionadas entre sí por principios comunicativos reguladores» (1972:12).

1. Principios constitutivos: reflejan la construcción del texto y la intención de los usuarios:

A) nociones centradas en el texto:

- cohesión: función comunicativa de la sintaxis: cada término lingüístico dirige el acceso a los otros elementos con los que se interrelaciona;

- coherencia: proceso cognitivo que pone en funcionamiento el lector por medio de inferencias para mantener la continuidad e interconectividad del sentido textual.

B) nociones centradas en las actitudes de los usuarios:

- intencionalidad: modalidades utilizadas por el productor para que se cumplan sus intenciones;

- aceptabilidad: actitud para participar en la interactividad y compartir la meta;

- informatividad: evaluación previsible o imprevisible del texto para los receptores;

- situacionalidad: factores relevantes en la situación comunicativa;

- intertextualidad: relación de dependencia respecto a textos anteriores.

2. Principios regulativos: control de la comunicación:

- eficacia: esfuerzo de los participantes en la utilización comunicativa;

- efectividad: condiciones favorables para alcanzar la meta comunicativa;

- adecuación: equilibrio del texto en el uso, situación y respeto de las normas de textualidad.

Por último, F. Rastier defiende que el texto es objeto empírico y real de la lingüística y que el sentido de un texto no es sólo accesible a la intuición sino que tiene que ser descrito racionalmente. A cada uno de los niveles tradicionales de la descripción lingüística -palabra, frase, texto- le hace correspon- 
der tres niveles: microsemántica, mesosemántica y macrosemántica: una frase no se reduce a una cadena de palabras, ni un texto a una suma de frases, ya que el sentido del texto no viene dado, sino construido en las estrategias de lectura. En su teoría de la interpretación defiende una semántica contextualizada porque el sentido se elabora en el contexto y en la situación, parámetros que permiten evaluar la posibilidad de diferentes recorridos interpretativos. En Arts et sciences du texte (2001), considera que el texto es la unidad esencial de transmisión de la cultura.

En cualquiera de las teorías se pone de manifiesto que la unidad fundamental de comunicación no es la oración, sino otra superior en la cual aquella queda integrada: el texto. Se podría definir siguiendo a Bernárdez (1995) como unidad mínima fundamental de comunicación, producto de la actividad verbal humana, que posee carácter social y caracterizada por su coherencia profunda y superficial, así como por su cierre semántico y formal. Y cuyos principales índices de textualidad, considerados como básicos, son: la coherencia -lógica, semántica y pragmática-, la cohesión y el cierre -semántico y formal-9 .

Nuestra noción de supertexto responde a los índices textuales arriba señalados en cuanto a unidad comunicativa verbal. Esta manera de concebir el texto responde al modelo clásico de la comunicación, y la encontramos también en la llamada metáfora del tubo que ve el lenguaje, el mensaje, el texto, en términos de una entidad física llena de cosas (contenido), a las que accede un receptor que ha de disponer de unas herramientas con las que conseguirá acceder al significado que dio origen al texto y, consecuentemente, a la intención comunicativa del productor del mismo. Pero es precisamente en esta nueva concepción textual cuando lo verbal no es suficiente para transmitir significado; donde un sonido (beep), una señal lumínica o un icono se une al mensaje verbal con el cual adquiere nuevo significado conjunto e indivisible para la generación de sentido.

Un claro ejemplo de esto es la utilización de los emoticonos ${ }^{10}$ que se emplean frecuentemente en mensajes de correo electrónico, blogs, foros, SMS, MMS, chats,... mediante servicios de mensajería instantánea. El significado de estos no sólo puede variar el sentido de la expresión verbal (con las implicaturas que ello conlleva) sino que en ocasiones sustituye a la propia lengua escrita. De

9 Estas características son aplicables, como veremos, al concepto de supertexto en lo que se refiere a su naturaleza puramente textual. A partir de aquí habrá que realizar los anclajes oportunos que lo separan y lo sitúan en una esfera mediática, electrónico-digital y/o virtual condicionante del acto de comunicación.

10 Un emoticono es una secuencia de caracteres ASCII que en su origen representaba una cara humana y expresaba una emoción. Posteriormente fueron creándose otros emoticonos con muy variados significados. Los emoticonos que expresan alegría u emociones positivas en general se clasifican normalmente como smileys. 
hecho, en los foros de Internet, los emoticonos se suelen reemplazar automáticamente por las imágenes correspondientes. Incluso, en algunos editores de texto (como Microsoft Word), la opción de «corrección automática» reconoce emoticonos básicos como :) y :(

\section{El supertexto en la era de la comunicación}

Esta propuesta textual entra dentro de un campo interdisciplinar de raíces antropológicas, semiótico-comunicativas y propiamente lingüísticas. Un estudio que, aunque toque campos no estrictamente lingüísticos, se hace necesario abordar. Ángel López García (1999:75) dice que la cultura actual se ha transformado convirtiéndose en audiovisual en lugar de escrita. «Y si la Lingüística aspira a ser una de las ciencias culturales del momento presente forzoso es que, como disciplina ocupada en desentrañar los fundamentos del acto comunicativo, tienda puentes hacia la modalidad más popular de la comunicación de fines del siglo XX, la audiovisual».

Enrique Bernárdez (2003: 9) señala que en nuestra cultura escrita, en la mayoría de las circunstancias de uso no formal, y sobre todo oral del lenguaje (y los soportes electrónicos han contribuido de manera extraordinaria a dotar de rasgos de oralidad a la lengua escrita), así como en casi la totalidad de los usos lingüísticos de muchas culturas: a) el texto no es único, ni tiene una forma definitiva; b) no existe un único significado, aparte imposiciones ideológicas, o, al menos, difícilmente comprobable; c) la individualidad del texto es muchas veces un mito; d) los receptores no se limitan a interpretar pasivamente el texto, sino que lo reciben activamente.

Ante esta situación se hace necesaria una serie de planteamientos previos. En primer lugar hay que considerar 1) la pluralidad de situaciones comunicativas y, por extensión, la diversidad de lenguajes con los que los participantes intervienen en el acto comunicativo. Se trata de poner de relieve la incidencia y dominio de los nuevos lenguajes audiovisuales, informativos y virtuales en el acto comunicativo tradicional -lingüístico-; 2) las exigencias que trae esta nueva visión de comunicación a la hora de seguir considerando como unidad mínima de comunicación al texto; y, por último, 3) la especialización de un determinado texto que se vale de un determinado soporte y que permite la elaboración de un nuevo tipo de texto al que llamamos supertexto.

\subsection{Pluralidad comunicativa y diversidad de lenguajes}

La delimitación de la comunicación como objeto científico tiene que extraerse de la realidad comunicativa concreta, de lo que se considera más 
relevante para ser estudiado de acuerdo con las exigencias de una determinada perspectiva científica o paradigma. Si nos detenemos en el objeto de estudio podemos descubrir entonces la pluralidad comunicativa que se desprende de las diferentes perspectivas de análisis empleadas. Dice Saperas (1998: 111-118):

Un diagnóstico general de esta compleja estructura comunicativa nos permite reconocer cinco niveles básicos de estructuración de los sistemas y procesos de comunicación, y consecuentemente define cinco niveles de análisis que organizan internamente la teoría de la comunicación: nivel intrapersonal, nivel interpersonal, nivel de organizaciones, nivel institucional (instituciones comunicativas) y nivel macrosocial (sociedad y opinión pública).

Esta enumeración subraya que las teorías actuales de la comunicación han de ampliar el objeto de estudio y campo de investigación como consecuencia de la necesidad de dar respuesta a una cada vez más compleja realidad comunicativa.

Wolton (1999) presenta una clasificación basada en los campos científicos que se ocupan de la comunicación, que incluye tres ámbitos diferentes. El primero, conectado con las neurociencias (neurobiología, neurofisiología, neurofarmacología, neuropsicología, informática) y con las ciencias cognitivas (psicolingüística, lógica, informática, psicología cognitiva, lingüística), se centra en el estudio de la comunicación en sus diferentes relaciones con el cerebro. El segundo ámbito entroncaría con las ciencias cognitivas y las ciencias para el ingeniero. Se centra en los problemas de comunicación entre el individuo y las máquinas. El tercer ámbito se centra en las ciencias humanas y sociales. Éste estudia el impacto y repercusión de las técnicas de comunicación (informática, telecomunicación audiovisual) en el funcionamiento de la sociedad. La interdisciplinariedad a la hora de abarcar el nuevo paradigma de la comunicación es más que manifiesta, y ello repercute en la reconsideración del proceso del acto comunicativo tradicional.

Es sabido que su enfoque depende de los intereses de la disciplina que se acerque a éste. Pero no hemos de obviar que en todas las perspectivas existen elementos constantes que, debido a su propia e ineludible dinámica, se repiten en todas ellas.

Según Serrano (1984, 37-51) la comunicación es

un proceso por el cual unos seres, unas personas, emisor y receptor/es, asignan significado a unos hechos producidos, y, entre ellos, muy especialmente al comportamiento de los otros seres o personas. [...] El concepto de comunicación presupone, pues, otros dos conceptos: el concepto de relación y el de transmisión. La relación es entre seres, entre personas, y la transmisión es de información, de significado. 
Nos encontramos entonces en el nivel de asignación de significado, es decir, en la semiosis. Esto es, se produce un proceso que se desarrolla en la mente del receptor; se inicia con la percepción del signo y finaliza con la presencia en su mente del objeto del signo y su significación. Se trata pues de un proceso inferenciall ${ }^{11}$.

Este proceso de comunicación, que se fundamenta en los conceptos de relación entre seres y de transmisión del mensaje, exige, además, la contribución de otros elementos que forman parte del mismo y ponen en contacto la relación y la transmisión: el contexto y el feedback o retroalimentación. La comunicación adquiere pues carácter de proceso, interactivo, simbólico, enmarcado en un espacio y tiempo y además, tal y como formula Rodrigo (2001: 46-48), a través de ella se constituye, se conforma, la realidad social que es compartida por una comunidad concreta, es conservada por las instituciones de esa misma sociedad y, además, es controlada con la finalidad de producir y conseguir determinados efectos; para ello se valdrá de diferentes lenguajes que le sirvan para tal fin.

La comunicación y sus lenguajes forman parte de la sociedad contemporánea. Ambos son el resultado de la incidencia de las llamadas nuevas tecnologías que forman parte de las nuevas formas de percibir, representar o comunicar.

Una transformación tecnológica de dimensiones históricas similares está ocurriendo 2.700 años después, a saber, la integración de varios modos de comunicación en una red interactiva. $\mathrm{O}$, en otras palabras, la formación de un supertexto y un metalenguaje que, por vez primera en la historia, integran en el mismo sistema las modalidades escrita, oral y audiovisual de la comunicación humana. [...] La integración potencial de texto, imágenes y sonido en el mismo sistema, interactuando desde puntos múltiples en un tiempo elegido (real o demorado) a lo largo de una red global, con un acceso abierto y asequible, cambia de forma fundamental el carácter de la comunicación. (Castells, 1997: 360)

Esta nueva realidad comunicativa exige un cambio de paradigma explicativo que supla las carencias e ineficacias científicas que no contemplan las actuales peculiaridades de los nuevos fenómenos comunicativos. Rojas-Vera y Arape (1998: 64) nos advierten de que la carencia conceptual actual hace que «la sociedad preinformacional tienda a simplificar el tema de sociedad de la información a sociedad informatizada, precisamente por existir un déficit conceptual. El mismo peligro corre al entender la idea de postcomunicación como una comunicación supertecnificada o simplemente hiperformatizada».

11 La comunicación verbal desde el punto de vista textual es de naturaleza semiótica e inferencial. En este sentido para comprender un mensaje se implican más operaciones que las empleadas en una mera descodificación. Para saber más sobre el proceso de inferencia y representación véase Cueto Vallverdú (2002: 44-49). 
Manuel Castells (1997) sostiene al respecto que las culturas están hechas de procesos de comunicación y todas las formas de comunicación se basan a su vez en la producción y el consumo de signos. Esta afirmación encaja con la idea de que en todas las sociedades, la humanidad ha actuado a través de un entorno simbólico. Por lo tanto, lo que es específico desde el punto de vista histórico del nuevo sistema de comunicación, organizado en torno a la integración electrónica de todos los modos de comunicación, desde el tipográfico hasta el multisensorial (que incluye el multimedial), no es su inducción a la realidad virtual sino, como subraya Castells, la construcción de una virtualidad real; es decir, que la realidad, tal y como se experimenta, siempre ha sido virtual en tanto que siempre se percibe a través de símbolos.

Esta nueva realidad comunicativa exige, tal y como señala Bernardo Paniagua $(2005,2006)$, que se reconozca no sólo la complejidad del lenguaje de los discursos mediáticos, sino también, como mínimo, la aceptación de esta realidad comunicativa en tres ámbitos del proceso de comunicación: el de la producción, el del producto o discurso y el del análisis e interpretación. Es decir, la tecnología ha propiciado que la especificidad del acto comunicativo no se reduce al producto textual final sino que abarca todo el proceso comunicativo. Por tanto, la emisión y recepción se verá afectada desde el origen, la intención comunicativa del hablante, hasta la asignación de significado e interpretación contextual final por la especial situación en la que se origina.

La sociedad actual, sociedad de la información, tal y como analizan (Echevarría, 1999, 2001; Castells, 2001) se caracteriza por las interrelaciones sociales que establecen sus miembros a través de unas modalidades de comunicación e información mediáticas, electrónicas y virtuales. Estas modalidades sobrepasan las formas de la comunicación oral y escrita que se convirtieron en el centro de todo interés científico anterior. Una sociedad a la que ya se ha definido como cibercultura o supercultura ${ }^{12}$, que incorporaría no sólo las características de este mundo supermoderno aparentemente anónimo y de los desechos culturales diseminados en lo que es llamado frecuentemente el mundo postmoderno, sino también las hechas de tradiciones y rasgos cultura-

12 Para Lull el concepto de supercultura

trasciende las categorías tradicionales de cultura y de análisis cultural. Este concepto continúa reflejando a la cultura como comunidad, tomando forma incluso en el nivel global, pero se basa principalmente en la idea de cultura como orientación y experiencia personal y en las formas dinámicas en que la interacción social significativa, las actividades y las identidades son construidas por las personas a través de las formas, los códigos y los procesos de la comunicación humana contemporáneos. Las superculturas son grupos establecidos, retículas y redes de relevancia personal intrincadas en complejas multiplicidades culturales que promueven el autoentendimiento, la pertenencia y la identidad, en tanto que proporcionan oportunidades de desarrollo personal, placer e influencia social. (Lull, 2009: 1). 
les más duraderos y sustantivos (Lull, 2001) y donde uno de sus ejemplos de mezclas y uniones hechas por los medios de comunicación es el supertexto tal y como lo concibe Castells ${ }^{13}$.

Desde estos presupuestos será preciso establecer los nuevos elementos constitutivos en el proceso de comunicación: producción, circulación y recepción para finalmente proponer un modelo de análisis para estudiar estos nuevos tipos de textos o supertextos que se generan y producen en ese contexto comunicativo, que Castells (2001) llama Galaxia Internet.

En primer lugar, los modelos de representación deberán integrar el factor tecnológico como elemento constitutivo en tanto que las tecnologías implementan de alguna manera la capacidad de producción y recepción comunicativa.

En segundo lugar, la incidencia tecnológica en el proceso comunicativo actual exige un análisis de la interpretación de la naturaleza y estructura de los productos dominantes en la interacción comunicativa ciberespacial bien sean hipertextuales, audiovisuales, electro-informáticos o virtuales.

Todo ello supone un proceso de análisis e investigación de carácter marcadamente interdisciplinar. Así para la noción de supertexto que aquí se presenta, a los índices textuales básicos como son la coherencia global e interna, la cohesión, la adecuación al contexto o el cierre semántico, habría que añadir otros rasgos como la multimedialidad, la ruptura de la secuencialidad y de la periodicidad, a los que se unen la interactividad y la legibilidad según Díaz Noci (2001: 85-119). Otro rasgo, si no definitivo, sí frecuente es el de la hipertextualidad ${ }^{14}$.

En tercer lugar, la caracterización general del lenguaje o discurso digital, de los elementos que conforman su estructura y de los nuevos géneros (el correo electrónico, el chat, el periodismo digital, las creaciones virtuales como foros, blogs, redes sociales...), tienen su especificidad en esta modalidad comunicativa.

Esto significa un proceso de comunicación (elementos, estructura y dinámica) particular que presenta novedades relevantes con respecto a la delimi-

13 Como ya se indicó al comienzo de este artículo, la concepción de supertexto que nosotros manejamos difiere en función y forma de la presentada por Castells. Para éste se trataría más bien de un texto híbrido, mezcla de lo visual y lo narrativo -real y ficcional- y que da como resultado un producto cultural. Para nosotros, la noción de supertexto hace hincapié en la especificidad del acto comunicativo que se da en la sociedad mediática y tecnificada que responde a las normas textuales "tradicionales" más otras propias derivadas de la situación concreta en la que se actualiza, y que condicionan todo el proceso de comunicación. 14 Se han dado muchas y variadas definiciones al concepto de hipertexto. En términos generales consideramos hipertexto un instrumento para organizar información, en el cual los datos se almacenan en una red de nodos conectados por enlaces. Los nodos contienen textos y si contienen además gráficos, imágenes, audio, animaciones y video, así como código ejecutable se les da el nombre de hipermedio. Para saber más véase Bianchini (1999). 
tación canónica de la comunicación. Por un lado, las exigencias en los agentes de la comunicación de su capacidad y competencia comunicativa con respecto a la producción y recepción de los productos digitales y, por otro, en la conformación de los lenguajes y soportes instrumentales a través de los cuales se vehiculiza esa interrelación comunicativa.

A este respecto, Alonso y Martínez (2003) caracterizan los medios digitales como digitales, interactivos, personalizados, multimedia, instantáneos, hipertextuales, universales e innovadores; y distinguen cinco criterios:

1) Objetivos o finalidad de la comunicación: Medios con finalidad informativa o noticiosa (cibermedios); medios con finalidad comunicativa o relacional (comunidades virtuales); medios con finalidad de servicio (aquí se incluirían los portales); y medios con finalidad de intermediación o infomediación (buscadores y directorios).

2) Contenidos: Deriva del anterior, subdividiéndose en a) información, b) servicios, c) comunicación o relaciones, y d) mediación o intermediación.

3) Audiencia / usuario: Hace referencia al público que pasa de circunscribirse a un papel de espectador más o menos pasivo (audiencia) a poder abarcar muy diversos papeles (usuario), desde el propio de la comunicación de masas hasta constituirse en emisor de información o interactuar con la misma de muy variadas formas.

4) Comunicador digital: Constata la variedad de las funciones que asume el emisor de la información, que se refieren a la creación y gestión de la tipología de contenidos reseñada anteriormente.

5) Herramientas para la interactividad: Se corresponde fundamentalmente con los medios de comunicación interpersonal, aunque también hace referencia al lenguaje estructurador de la comunicación.

Por su parte, Guillermo López García (2005) establece una clasificación para los medios de comunicación digital partiendo de una doble perspectiva:

A. Medios de comunicación interpersonal:

1. comunicación sincrónica: chats, redes P2P y juegos en red.

2. comunicación asincrónica: E-mails, listas de distribución, grupos de noticias, foros de debate, wikis, encuestas, comunidades virtuales.

Distingue entre comunicación sincrónica y comunicación asincrónica en función del carácter simultáneo o no de la comunicación establecida.

B. Medios de comunicación colectiva:

1. medios de representación -medios de comunicación colectiva surgidos con la función primordial de reproducir la estructura social cuyo principal objetivo es su representación informática-: Páginas personales, weblogs o bitácoras, páginas de asociaciones, instituciones y empresas. 
2. medios globales -su origen es el mismo hecho comunicativo, el ofrecimiento de unos determinados contenidos a un público-: Portales y cibermedios.

Visto de este modo, el discurso mediático audiovisual es el resultado de la complementariedad de un conjunto de signos o sistemas plurales que se interrelacionan e interactúan dentro de un sistema más complejo propio de un medio y, dentro de él, en un programa determinado donde adquieren su especificidad mediática. Los supertextos se conformarían respetando en sus diferentes tipos y géneros textuales las propiedades que los definen genéricamente, aunque se realicen de formas específicas.

\subsection{Un nuevo enfoque para la comunicación}

Hablar de pluralidad comunicativa conlleva asumir la correspondiente diversidad de construcciones discursivas y textuales como instrumentos indispensables para que pueda darse una eficaz interacción comunicativa y social. Al mismo tiempo, y de acuerdo con los supuestos de la Lingüística del Texto, esa eficacia es deudora de la competencia comunicativa, textual y lingüística por parte de los emisores y receptores, agentes de la comunicación, que conforman e interpretan los textos cumpliendo propiedades constituyentes: coherencia, cohesión y adecuación.

Por esta misma razón, se ha de aludir al lenguaje en la delimitación de la comunicación como proceso en el que interactúan individuos y colectividades por medio de producción, transmisión, comprensión e interpretación de unos mensajes que exigen su plasmación y conformación a través del uso de lenguajes codificados de forma específica en función de la peculiaridad histórica que define la interacción comunicativa.

Tradicionalmente los estudios sobre el lenguaje han abordado su análisis desde una doble perspectiva. Por un lado, la que se relaciona con el lenguaje como facultad o capacidad específicamente humana para inventar un conjunto de signos de carácter eminentemente arbitrario y simbólico. Por otra parte, aquella que trata el lenguaje como un sistema semiótico-lingüístico que sirve de interrelación entre humanos y que centra su atención en las unidades sígnicas, en las normas para codificarlas y en la inclusión de las mismas en los niveles del lenguaje.

El primer enfoque tiene naturaleza social, que se deriva del carácter simbólico y neurológico del lenguaje; el segundo versa principalmente de la naturaleza y estructura de los signos lingüísticos, de los niveles del lenguaje y de las unidades de la comunicación (Moreno, 1991). Pero para una definición completa del lenguaje no se ha de olvidar su carácter comunicativo 
intencional frente al meramente informativo. El lenguaje adquiere su auténtica dimensión como elemento y factor indispensable para que la comunicación entre emisores y receptores tenga lugar de modo adecuado y eficaz.

De esta manera, la construcción de los textos o discursos como transmisores de intencionalidades a través de las funciones comunicativas supone la interacción entre el lenguaje definido como facultad humana y el lenguaje como sistema sígnico, más allá de la naturaleza de los signos empleados. Es aquí cuando tiene cabida la utilización de signos de naturaleza no lingüística posibles a las nuevas tecnologías de la información y comunicación que se combinan, sustituyen, modifican y superponen en el acto comunicativo.

Las nuevas tecnologías han propiciado que los actos de comunicación se produzcan y desarrollen con unas características propias con respecto a la definición canónica de comunicación. Peculiaridades que son manifiestas en la transmisión de información, y, por ende, de significado dentro de un acto comunicativo.

Ramón Salaverría (2004) incide en las distintas formas de difusión de la información. Nos habla de:

1) Autoría: individual / colectiva / institucional (de carácter privado o público).

2) Direccionalidad: unidireccional / bidireccional / multidireccional. Hace referencia al grado de jerarquización de las condiciones en que se da la comunicación, esto es, a su verticalidad u horizontalidad.

3) Visibilidad: privada / pública: medios de acceso público o medios que requieren suscripción previa.

4) Acceso: recepción / consulta / búsqueda. Se centra en analizar los criterios que sigue el usuario en su consumo de contenidos.

5) Temporalidad: simultánea / diferida. Hace referencia al carácter sincrónico o asincrónico del acceso a la información.

Salaverría insiste en que los contenidos multimedia que caracterizan a las vanguardias del XXI exigen un nuevo lenguaje que ha de llevar a una convergencia tecnológica en los medios de comunicación principalmente en tres ámbitos: convergencia de redes, convergencia instrumental, convergencia de aplicaciones ${ }^{15}$.

15 Salaverría analiza el impacto de la tecnología digital en la sociedad, un impacto que ha condicionado concretamente la evolución de numerosas profesiones, entre ellas la del periodismo. Nos habla del proceso de mutación del concepto de medio de comunicación cuya consecuencia primera la encontramos en la búsqueda, elaboración y difusión de los contenidos informativos. Véase Salaverría (2008). 
Sea cual sea el tipo de difusión de la información que se dé, es preciso insistir en que en este tipo de actos comunicativos existe una interrelación entre el lenguaje natural y otros lenguajes (sistemas de signos) que adquieren relevancia especial en función de la modalidad o género textual. Tanto la relación como la relevancia pueden explicarse desde perspectivas diferentes y, entre ellas, la denominada cognitiva y gestáltica (López García, 1989; 1992). La perspectiva gestáltica ${ }^{16}$ toma los conceptos de fondo y figura y su relación como ejes fundamentales de la dinámica explicativa en el proceso de comunicación. Desde este punto de vista, el lenguaje natural, oral o escrito, funcionaría como fondo de la figura de los supertextos en determinadas fases del proceso de su producción y recepción.

\subsection{Supertexto}

En una primera y general aproximación ya nos hemos referido a la aparición del concepto de multimedia como clave a su vez para asumir la existencia del de supertexto. El problema viene cuando se quiere reducir la especificidad de este nuevo tipo de producción a una cuestión de soporte. Pretendemos incluir esta unidad textual en otra perspectiva dentro del proceso de comunicación global y mediático determinado socialmente por el momento histórico -mediático y tecnológico- en el que nos encontramos.

A pesar de la falta de consenso y las numerosas definiciones que se han dado, se puede entender por multimedia un sistema que utiliza más de un medio de comunicación al mismo tiempo en la presentación de la información, como texto, imagen, animación, vídeo y sonido. Consiste, por tanto, en un sistema que utiliza informaciones almacenadas o controladas digitalmente (texto, gráficos, animación, voz y vídeo) que se combinan para formar un único producto.

A su vez, la utilización de técnicas multimediales con los ordenadores permitió el desarrollo del hipertexto de modo que se pudiera acceder a determi-

16 Las leyes de la percepción fueron enunciadas por los psicólogos Max Wertheimer, Wolfgang Köhler y Kurt Koffka, quienes observaron que el cerebro humano organiza las percepciones como totalidades (Gestalts) de acuerdo con ciertas leyes a las que denominaron "leyes de la percepción". Estas leyes enuncian principios generales, presentes en cada acto perceptivo demostrando que el cerebro hace la mejor organización posible de los elementos que percibe, y asimismo explican cómo se configura esa mejor organización posible a través de varios principios reformulados como leyes. Posteriormente estas leyes enfocaron su atención ya no en una percepción en un momento concreto, sino del universo cognoscible como totalidad. Estas leyes serán tomadas por diversas disciplinas en ámbitos diversos como la comunicación, la sociología, la psicología social, la ecología o la arquitectura. En el ámbito español destacará la denominada Gramática Liminar surgida en la Universitat de València en la década de los ochenta en torno a las ideas gestálticas, emparentada con la rama europea de la lingüística cognitiva. 
nada información en uno o varios documentos simplemente pinchando en las palabras remarcadas relacionadas.

Pero la vinculación interactiva no se limita a los textos, sino que también se puede interactuar con sonidos, animaciones y servicios de Internet relacionados con el tema, lo cual ha dado origen a un nuevo concepto que se ha llamado hipermedia, fusión de los conceptos hipertexto y multimedia. Los sistemas de hipermedios funcionan como organizadores de información textual, gráfica y sonora a través de vínculos que crean asociaciones entre información relacionada dentro del sistema ${ }^{17}$.

De esta manera, cualquier texto producido a partir de la utilización de nuevos soportes informáticos, electrónicos y/o virtuales es susceptible de considerarse supertexto si, dada una unidad lingüística comunicativa que concreta una actividad verbal con carácter social en que la intención del hablante produce un cierre semántico-comunicativo, necesita para su construcción signos de naturaleza no lingüística, posibles a las nuevas tecnologías de la información y comunicación, que se combinan, modifican, sustituyen, y superponen en todo el acto comunicativo, y que dotan al (super-)texto resultante de autonomía.

La caracterización de los lenguajes y soportes instrumentales a través de los cuales se vehiculiza esa interrelación comunicativa, así como la aparición de los nuevos géneros (el correo electrónico, SMS, chats, las creaciones virtuales como foros, blogs, redes sociales...) han permitido la aparición de esta nueva clase de textos en los que también se ve afectado el mismo acto comunicativo. Concretemos en un ejemplo.

Un MMS (Multimedia Message System) ${ }^{18}$, se enmarca dentro de un acto comunicativo que sobrepasa la definición ortodoxa de texto. Para ello, el texto resultante del acto comunicativo (supertexto), además de las exigencias multimediales, ha de cumplir las propiamente textuales que le doten de coherencia y sentido autónomo. El MMS es un ejemplo claro de nuevos textos en donde lo lingüístico y lo no lingüístico cooperan para transmitir información comunicativa, pues estos tipos de textos pueden llegar a constituirse como una unidad superior de comunicación que actualmente incluya diversos formatos de contenido: imágenes, texto (normal o de memoria expandida), sonido y vídeo.

17 Para saber más sobre los términos multimedia e hipermedia véanse Vaughan (1994); Brauner y Bickmann (1996).

18 Este medio constituye una versión mejorada de SMS (Short Message Service), ya que éste es sólo para texto. Con MMS se pueden enviar y recibir además datos multimedia (como fotos digitales, video, imágenes, etc.). También se pueden enviar y recibir mensajes MMS a Internet utilizando WAP, preferiblemente con un móvil que tenga GPRS para tener la velocidad necesaria. 
En el acto de comunicación que se establece con un MMS nos encontramos con un texto si se enmarca en un proceso que responda a los índices de coherencia (se centra en un tópico discursivo), cohesión ${ }^{19}$, es adecuado al destinatario y, además, ofrece toda la información necesaria. Ha de contar igualmente con una intención comunicativa y para ello hará uso de estrategias pertinentes para alcanzar la eficacia y eficiencia comunicativa. Se ha de enmarcar también en una situación comunicativa concreta, lo que permite configurar un horizonte de expectativas y un contexto para su interpretación y comprensión.

Pero además nos encontramos una característica restringida a este tipo de textos. A los índices textuales anteriores se une el de la multimedialidad, es decir, la digitalización de contenidos y la convergencia tecnológica, que comportan cambios de gran alcance en el sistema audiovisual, ya no sólo en el mensaje mismo, sino para la intención comunicativa y la asignación de significado.

Si analizamos el proceso de comunicación que tiene lugar mediante un MMS (y en general todos los textos producidos digitalmente), comprobamos que la naturaleza específica del acto conforma no sólo la codificación del texto sino la misma intención comunicativa. Las posibilidades tecnológicas disponibles hacen que la intención comunicativa se vea afectada por la necesidad de comunicarse a través del medio electrónico. En la construcción del supertexto el agente puede aplicar una multiplicidad de narrativas visuales, auditivas, lingüísticas y no lingüísticas que combinándose adecuadamente dotan al supertexto de coherencia y cohesión y permiten al receptor asignar significado y comprender su sentido. Así, un mensaje verbal puede combinarse, por ejemplo, con imágenes, sonidos, o vibraciones. Es más, dentro del mensaje escrito, una unidad léxica puede estar formada mediante grafemas / fonemas e imágenes o sonidos de manera unitaria. Es frecuente encontrar en este tipo de lenguajes palabras que combinan grafemas con emoticonos o guiños que sustituyen alguna sílaba de la palabra. Ejemplo: «estoy traba: -D ndo 4 horas al día» en lugar de «estoy trabajando 4 horas al día».

Pero además el proceso de recepción tiene sus propias particularidades. El contacto entre los participantes en la comunicación puede darse con un

19 Cuestión aparte constituye la utilización del leguaje SMS (lenguaje a/gramatical). En este caso concreto, la limitación de los mensajes, la reducida interfaz de los móviles y el propio lenguaje de los chats contribuyen a que los usuarios del servicio desarrollen un uso intensivo de las abreviaturas, economía de caracteres, que también supone la sustitución de determinados fonemas por números, iconos y la omisión de vocales y/o consonantes. Este problema añadido hace que muchas veces pueda hacerse ineficaz la comunicación. A pesar de ello, esta peculiaridad gramatical es resuelta en el propio acto de comunicación por el conocimiento mutuo del código utilizado por parte de los agentes. 
aviso sonoro (beep), llamada auditiva (sonido), visual (luminosa) o táctil (vibración) -diversidad de lenguajes- que permite al destinatario decidir si establecer o proseguir sincrónica o asincrónicamente el intercambio comunicativo con el emisor.

Tanto en el proceso de emisión como en el de recepción se nos permite romper la secuencialidad, o la interacción. El mensaje podrá darse en un proceso de comunicación bidireccional o multidireccional que permita al receptor dar respuesta al emisor (feedback o regulación) y además en un tiempo simultáneo o diferido y en un espacio global. Esta última característica es la que permite la Globalización ${ }^{20}$.

Por tanto, la noción de supertexto, tal y como la hemos planteado aquí, debe responder a una doble mixtura: la textual, que en términos gestálticos funcionaría como fondo y la multimedial que funcionaría como figura, cuya interrelación daría sentido último al acto de comunicación dotando a la unidad comunicativa resultante de autosemanticidad.

\section{Conclusiones}

El concepto de supertexto coloca a la lengua y a la lingüística comunicativa en una nueva dimensión, donde el texto definido tal y como lo hace la Lingüística del Habla se muestra limitado o insuficiente. La aproximación lingüística a esa realidad comunicativa presentaría dos posibilidades (Bernardo Paniagua, 2005): La primera, cuando el lenguaje natural aparece en los discursos mediáticos como formante indispensable y, por tanto, se atiende a un enfoque más específicamente lingüístico. La segunda, cuando el lenguaje natural no se considera como objeto autónomo sino como un formante que interactúa con otros lenguajes del discurso mediático estructurado como objeto complejo. En este sentido, la Lingüística es incapaz de actuar en este nuevo ámbito de la teoría de la comunicación. Por tanto, la Lingüística debería desarrollar un modelo para interpretar este nuevo discurso mediático, así al supertexto.

Fandos Igado propone que la nueva sociedad de la información supone un nuevo paradigma cultural ineludible que ha supuesto una integración semiótica (y compleja) frente a la diversidad histórica tradicional (2008: 79):

En el entorno natural y en el entorno urbano han surgido diferentes sistemas de signos para desarrollar procesos semióticos (habla, escritura, músi-

20 Las redes telemáticas de banda ancha permiten transportar ficheros informáticos que contienen textos, imágenes y sonidos a cualquier lugar del mundo donde llegue la línea telefónica. Además la transformación de átomos en bits permite desmaterializar las imágenes (textos), posibilidad que favorece la eliminación de cualquier referencia a una única obra. 
ca, dibujo...). La diversidad semiótica es tan grande que personas de culturas diferentes pueden llegar a tener serias dificultades para comunicarse y entenderse. Esta enorme diversidad provoca la separación, disgregación e incomunicación de las diferentes culturas. En el tercer entorno se mantiene esa diversidad de sistemas de signos pero con la capacidad de integrarlos en un mismo sistema semiótico: el sistema digital y binario basado en bits, pixels y lenguajes de programación.

En este contexto cultural es cuando cobra sentido la noción de supertexto que se enmarca dentro de un acto comunicativo que sobrepasa la definición tradicional de texto ya que:

1. cumple las características propiamente textuales que le dotan de coherencia externa e interna y autosemanticidad, pero que

2. lo propiamente lingüístico coopera con lo no lingüístico para transmitir significado comunicativo, pues es característico que en este tipo de mensajes se den diversos formatos de contenido: imágenes, texto, sonido y vídeo.

3. Los actos de comunicación que se establecen dentro de esta convergencia tecnológica comportan cambios de gran alcance ya no sólo en el mensaje mismo, sino para la intención comunicativa y la asignación de significado.

4. En la emisión/recepción del supertexto los agentes sociales pueden aplicar una multiplicidad de narrativas visuales, auditivas, lingüísticas y no lingüísticas que dadas sus características intrínsecas permiten a los participantes establecer o proseguir el acto comunicativo sincrónica o asincrónicamente.

5. El acto comunicativo también sufre variaciones ya que tanto en el proceso de emisión como en el de recepción, se nos permite romper la secuencialidad o la interacción. El mensaje puede darse en un proceso de comunicación bidireccional o multidireccional que permita al receptor dar respuesta al emisor (feedback o regulación) en un tiempo simultáneo o diferido y en un espacio individual o global.

Nos encontramos en un ámbito pendiente de tradición investigadora pero que, en una primera aproximación, observamos que sobrepasa lo puramente lingüístico. De aquí su carácter interdisciplinar. No se reduce a una distinción entre lo lingüístico y medial, puesto que nos situamos en otro nivel de estudio. Se trata más bien de una imbricación entre lo estrictamente textual y lo mediático, eléctrico o virtual que no sólo condiciona el anterior, sino que toma cuerpo de discurso en el proceso comunicativo. Lo significativo no vendrá constituido exclusivamente por un lenguaje lingüístico sino por una multiplicidad de lenguajes. El mensaje se verá condicionado y transformado, pero también la finalidad comunicativa; no sólo se verán afectadas las condiciones de emisor y 
emisión o las de recepción y destinatario sino la propia situación contextual que, entre otras peculiaridades, podrá ser multidireccional y multicrónica.

\section{Referencias bibliográficas}

Alonso, J. y Martínez, L. (2003): "Medios interactivos: caracterización y contenidos" en Díaz Noci, J. y Salaverría, R.: Manual de redacción ciberperiodística. Barcelona, Ariel.

Bastardas Boada, A. (1999): "Lingüística general y teorías de la complejidad ecológica: algunas ideas desde una transdisciplinariedad sugerente", en Fernández J.: Lingüística para el siglo XXI. Salamanca, Universidad de Salamanca.

Benveniste, E. (1974a): "Los niveles del análisis lingüístico", en Problemas de lingüística general, I, Siglo XXI, México, págs. 118-130.

Benveniste, E (1974b): "De la subjetividad en el lenguaje", en Problemas de lingüística general, I, o. c., págs.179-187.

Bernárdez, E. (1995): Teoría y epistemología del texto, Madrid, Cátedra.

Bernárdez, E. (2003): "El texto en el proceso comunicativo", en Revista de investigación lingüística, $\mathrm{N}^{\mathrm{o}} 2$ - Vol. VI, págs. 7-28.

Bernardo Paniagua, J.M. (2005): "Comunicación y lenguaje”, en López, A. y Gallardo, B.: Conocimiento y lenguaje. Valencia, PUV.

Bernardo Paniagua, J.M. (2006): El sistema de la comunicación mediática. Valencia, Tirant lo Blanch.

Beugrande, R-A. de, y Dressler, W.U. (1972 /1997): Introducción a la lingüística del texto, Barcelona, Ariel.

Bianchini, A. (1999): "Conceptos y definiciones de hipertexto". Caracas, Universidad Simón Bolivar. Disponible en: http://www.ldc.usb.ve/ abianc/hipertexto.pdf (2411-2009).

Brauner, J. y Bickmann, R. (1996): La sociedad multimedia: Las futuras aplicaciones del audio-video, la informática y las telecomunicaciones. Barcelona, Gedisa.

Cueto Vallverdú, N. (2002): Representación e Inferencia. El proceso de la interpretación. Oviedo. Universidad de Oviedo.

Castells, M. (1996, 1997): La era de la información. Madrid, Alianza, 3 vols.

Castells, M. (2001): La Galaxia Internet. Madrid, Areté.

Díaz Noci, J. (2001): La escritura digital. Hipertexto y construcción del discurso informativo en el periodismo electrónico. Guipúzcoa, Universidad del País Vasco.

Echevarría, J. (1999): Los señores del aire: Telépolis y el tercer entorno. Barcelona, Destino. Echevarría, J. (2001): Un mundo virtual. Barcelona, Plaza y Janés.

Enkvist, N.E. (1991) "Discourse strategies and discourse types", E. Ventola (ed.) Functional and systemic linguistics: approaches and uses, Berlin, Mouton de Gruyter.

Fandos Igado, M. (2007): La temática en los procesos educativos "Educans": propuesta de una plataforma abierta para la Educación Secundaria Obligatoria. Tesis doctoral. Huelva, Universidad de Huelva. Disponible en: rabida.uhu.es/dspace/bitstream/10272/64/1/12736314.pdf (2-12-2009). 
López García, Á. (1989; 1992): Fundamentos de lingüística perceptiva. Madrid, Gredos. López García, Á. (1999): "Lingüística y comunicación audiovisual”, en Fernández J.: Lingüística para el siglo XXI. Salamanca, Universidad de Salamanca, págs. 73-96. López García, G. (2005): Modelos de comunicación en Internet. Valencia: Tirant lo Blanch. Lull, J. (2000): Media, Communication, Culture: A Global Approach (Revised ed.). Cambridge, UK: Polity Press; New York: Columbia University Press.

Lull, J. (2009): “Supercultura para la comunicación". James Lull on line. Portal español. Disponible en: http://www.jameslull.com/supercultura.html (23-11-2009).

Moreno, J.C. (1991): Curso universitario de Lingüística General. Madrid, Síntesis, 2 vols. Morin, E. (1991): La méthode. 4: Les idées: Leur habitat, leur vie, leurs moeurs, leur organisation, Paris, Seuil.

Morin, E. (1992): Introduction à la pensée complexe, Paris, ESF.

Morin, E. (1999): "Lintelligence de la complexité. Entretien avec Edgar Morin" en Spire, A. (1999), págs. 169 y ss.

Rastier, F. (2001): Arts et sciences du text. Paris, Seuil.

Rodrigo, M. (2001): Teorías de la comunicación. Valencia, Universidad de Valencia.

Rojas-Vera, L.R. y Arape Capelo, E. (1998): "Hacia la poscomunicación". Quark, 4: 64-80.

Salaverría, R. (2004): Redacción periodística en Internet. Pamplona, Eunsa.

Salaverría, R. (2008): "La convergencia tecnológica en los medios de comunicación: retos para el periodismo". Trípodos, núm. 23. En: http://www.tripodos.com/pdf/ Salaverr\%C3\%ADayGarc\%C3\%ADaAvil\%C3\%A9s.pdf84.pdf (24-11-2009).

Saperas, E. (1998): Manual básico de Teoría de la Comunicación. Barcelona, CIMS.

Serrano, S. (1984): La Semiótica. Barcelona, Montesinos.

Vaughan, T. (1994, $2^{a}$ edición): Todo el poder de la Multimedia. México, Mc Graw Hill. Wolton, D. (1999): Sobre la comunicación. Madrid, Acento. 